\title{
IMPACT OF COLOR ON OUR
}

Rana Sabyasachi

Assistant Professor (Painting),

Subharti Institute of Fine Arts \& Fashion Design (SIFF), Subharti University,

Delhi-Haridwar Bypass road, Meerut.

E-mail-sabyrana@gmail.com

\begin{abstract}
There are many colors in our world. Think of how bland and unexciting it would be without color. Colors light up our surroundings, and inspire us to be creative. Life would have been terribly drab if colors did not exist. I cannot imagine a world where there was a total absence of color. It is enough for us to look at the dawn after the darkness of night to know the difference. Landscapes and seascapes take life from the different shades of greens and blues, the colors of the birds' feathers, the different colors of fish, and the multicolored flowers.

Color is ubiquitous and is a source of information. People make up their minds within 90 seconds of their initial interactions with either people or products. About 62-90 percent of the assessment is based on colors alone. So, prudent use of colors can contribute not only to differentiating products from competitors, but also to influencing moods and feelings positively or negatively. Colors affect different people in different ways. Colors can certainly alter our mood or have a positive or negative impact on us even though many of us are not aware about it. Colors can affect our moods and mental state. According to Britannica, the most important aspect of color in daily life is probably the one that is least defined and most variable. It involves aesthetic and psychological responses to color and influences art, fashion, commerce, and even physical and emotional sensations. To sum up, colors are a very big part of our world; moreover, it makes living more cheerful and lets us to enjoy the diversity.
\end{abstract}

Colors are used for many purposes, ranging from medicine to art, politics to anthropology. They are an indispensable ingredient of our lives. But no matter how they are used, the best use of colors is observed in the works of the Great Artist.

Let's travel through the wonderful world of colors. Each color conceals a story. Some virtuous and sensitive eyes see the truth through them, while others see rage, anger, and all the evils dictated by the alter ego. Colors carry such feelings as anger and hope, and symbolize such concepts as sinfulness and innocence. They are abused or sacrificed, and widely preferred or despised. 